\title{
THE RELATIONSHIP BETWEEN ELECTRICAL PROPERTIES AND INTERBAND AND INTRABAND TRANSITIONS OF THIN $\mathrm{Cr}$ FILMS \\ S.S. Fouad, A. H. Ammar, and M. H. El-Fazary Facutly o Education, Ain Shans Universily. Cairo, Egypt.
}

\section{ABSTRACT}

Thin chromitum films of thickness ranging from (25 to $80 \mathrm{rm}$ ) were prepared by thernal evaporation under a vacuon of $10^{-5}$ Torr. The electrical resistivity was intersely proportional to the thickness of the film. Analysis of the electrical resistivity was treated in the frame of the effective mean free porn sheory of size effect developed by Tellier et al. Such analysis allows the deternination of the mean free path $l_{o}$, carrier concensration $n_{c}$, relaxation time $t$ and the Fermi energy $F_{F}$, The optical constants ( $n$ and $K$ ) of chronlian thin films were determined in the specral range of (200 to $25000 \mathrm{rm}$ ). The obrained results agree with the optical condactivities predicted theoretically by Monuzi et al. In addition, the values of $n_{c}, \sigma, l_{\theta}$, and robtained elecrrically were folot to match with those obtained opticully.

\section{INTRODUCTION}

The theoretical calculations of the optical constants of metals might be interesting as there is an aceumulating anoumt of experimental Jata which now become sufficient to allow comparison with theory. Moreover the theory might indicate where turther measurements of the cptical constants are needed to give more information on the band structure of metalsul. However, band structure calculations for some of we cransition metals have heen performed, and in a few recent cases the 
calculated band structe has been ust to oblain theortical values for the interband optical absorption |3:

In the present study, electrical resistivily and opical constants have been obtained. The resuls were used to estimate the parameter of mean frec path. carrier concentration, Fermi energy. Moreover, the contributions of intertand as well as the incraband tristions have been extacted from the optical measurements.

\section{EXPERIMENTAL TECHNIQUE.}

This films of chromiun Cr (purity $99.99 \%)$ were prepared in vacuum of $10^{5}$ Tor by thennal craporation on glass quart and poussum bromide substrates beld at room temperature, In all cases the cleaned substrates were masked until the source was at is evaporation temperature, and the evaporation rate was made as high as possible. the thicknesses of the films were deternined with a multiple-bean interteroneter of the Fizeau type. The electical resistivity ( $\rho$ ) of the samples was measured by the two-probe tectnique using a bighly sensitive digital multineter (type

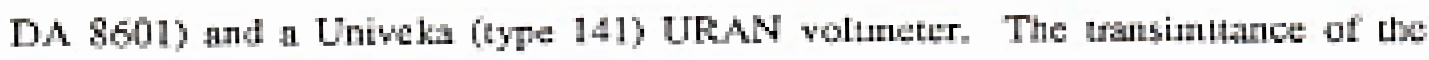
prepared suaples were measured at nomal incidence in the spectral tange 200 to 2000 na using a Carey 2390 spctrophotomettr, and in the spectral mage 2500 to $25000 \mathrm{~m}$ using Pycunicam 3P3-3001R spectrophotonteter.

\section{3 - RESULTS AND DISCUSSION}

\section{1. : Electrical Resistivity}

The electrical resistivity (p) of Cr tilms as a function of thickness ( $\mathrm{t}$ ) is shown in Fig. (1). The dan follow the known behaviour, where decreases by increasing t. The Fuchs-Sondleiner expresion was used (4) to analyse the thickness dependence of the resistivily taking the surfuce scatering into account, along with the other kinds of scattering. Structural studis indicate that thin Cf films are polycrystalline[s]: thus graia-boundary scattering also should the taken into accounc along with the surtace scatding, when discussing the experimenal results on film poperties. The Mayada- 


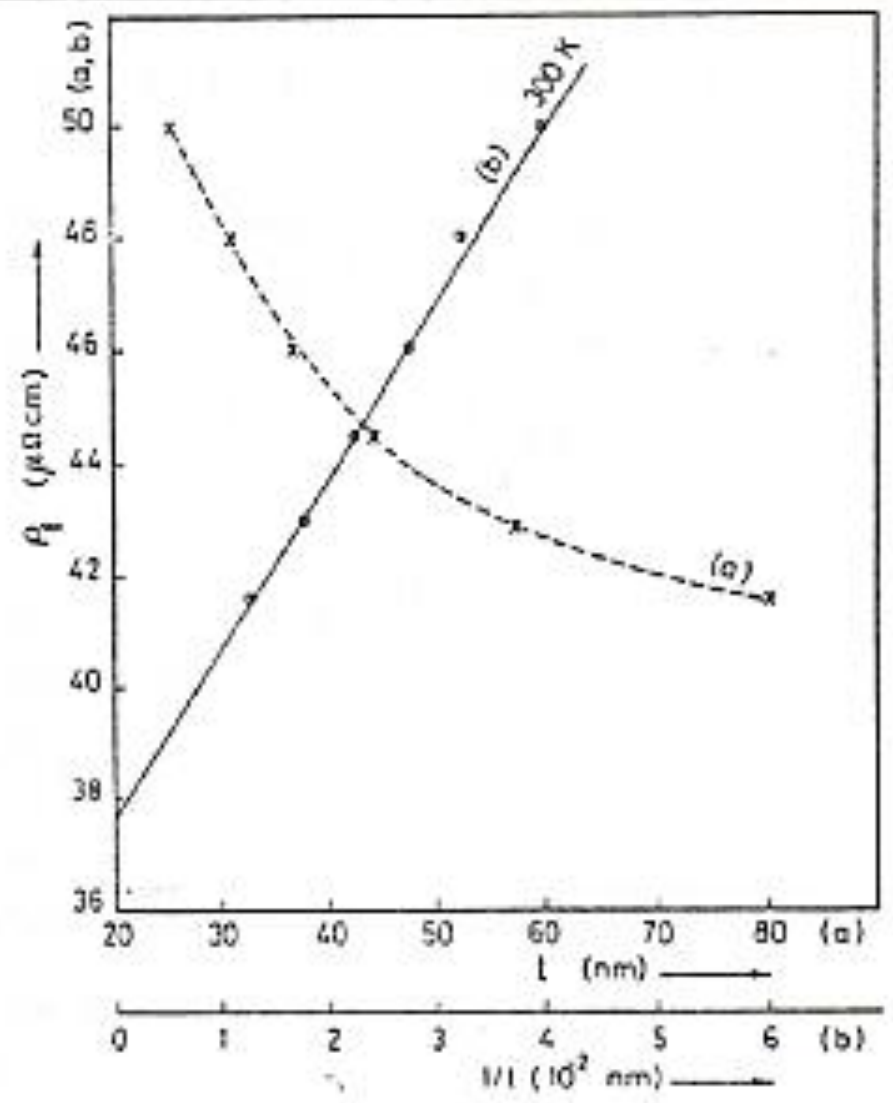

Fig. 1. (a) Relation betwcen the thickness ( 1 ) of the $\mathrm{Cr}$ films and the corresponding resistivily $(\rho)$.

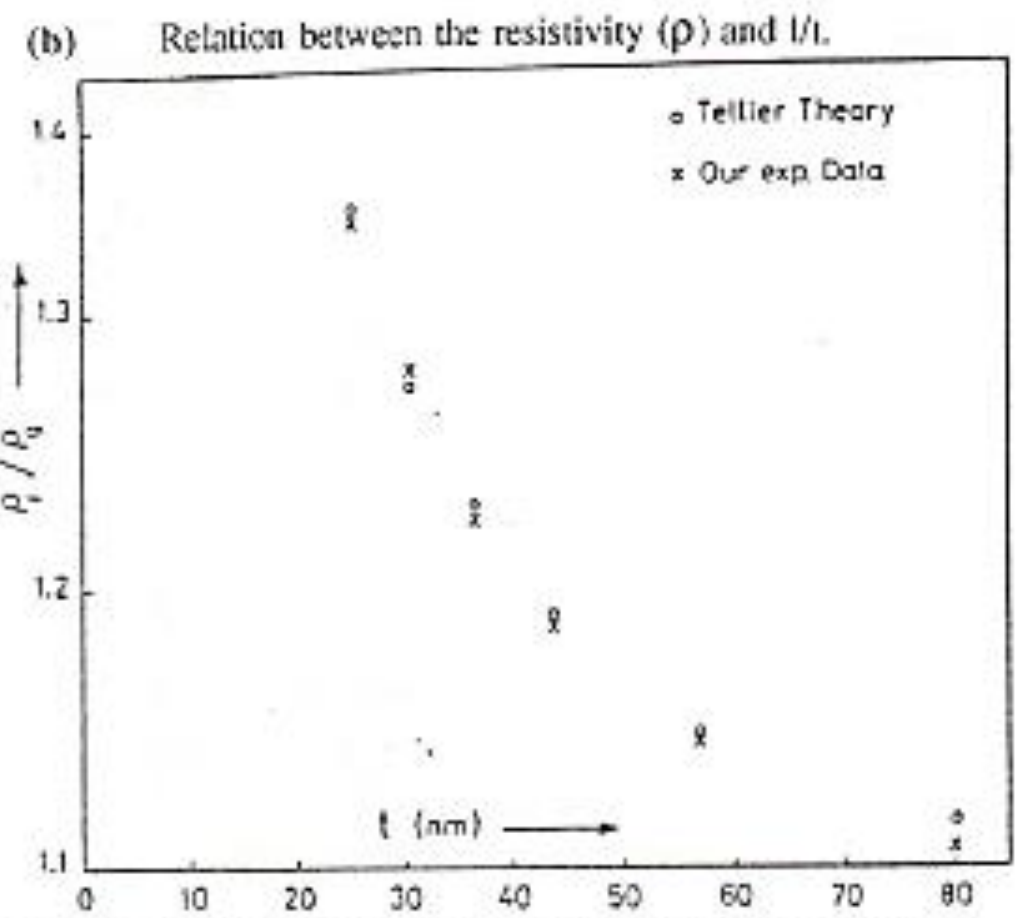

Fig. 2. Relation becween the nesistivity ratio $\left(\rho_{l} / \rho_{g}\right)$ and thickness $L$ 
Shatzkes theory takes into account the grain boundary scatting, but its expression [6] is complicated. Mola and Heras[7], Tellier et al. [8] and Tellier et al.[9] attempted to simplify the analytical expressions of Mayadas-Shatzkes theory. Tellier et al.[9] derived such a simple analytical expression defining an effective mean free path in an infinitely thick film. This model is known as the effective mean free path model. According to which the analytical expression for the film resistivity as a function of thickness is given by :

$$
\rho_{\mathrm{f}}=\rho_{\mathrm{g}}\left[1-\frac{3}{8} \frac{1-\rho}{\mathrm{K}}\right] \int_{\mathrm{g}}^{\mathrm{x}}\left(\frac{1}{\mathrm{x}^{3}}-\frac{1}{\mathrm{x}^{5}}\right)\left[\frac{1-\exp (-\mathrm{x})}{1-\operatorname{Pexp}(-\mathrm{x})}\right]
$$

where $\rho_{g}$ is the resistivity of the infinitely thick film, $K_{g}$ is the reduced thickness $(\mathrm{U} / \mathrm{g})$. Under asymptotic conditions, $\mathrm{K}_{\mathrm{g}} \gg>1$, the above equation can be reduced to the form :

$$
\rho_{\mathrm{f}}=\rho_{\mathrm{g}}\left[1-\frac{3}{8} \frac{\mathrm{L}_{\mathrm{g}}}{\mathrm{t}}(1-\mathrm{p})\right]
$$

It has been shown numerically that the above expression is successfully applicable down to $\mathrm{K}_{\mathrm{g}}=0.1$. It is evident from the above experession that a plot of film resistivity as a function of reciprocal thickness will be linear at a given fixed temperature. Obtained resistivity exhibits linear dependence on 1/t (Fig. 1), which agrees with equation (2). Estimated value of $\rho_{0}$ was found to be $37.7 \mu \Omega \mathrm{cm}$ for $\mathrm{Cr}$ films at $300^{\circ} \mathrm{K}$. From the slope of the graph, the effective mean free path of carriers, $\mathrm{L}_{\mathrm{o}}$ at at $300{ }^{\circ} \mathrm{K}$ was found to be $22.5 \mathrm{~nm}$. There values differ from those given by Udachan et al. [10] in $\rho_{0}=50 \mu \Omega \mathrm{cm}$ and $L_{0}=107 \mathrm{~nm}$ with $p=0.3$. This difference can be can be accounted for by the fact that Udachan et al. [10] in their study used Fuchs-Sondheimer [4] theory which does not consider the grain-boundary scattering also we can't ignore the difference in purity and condition of preparation, the latter greatly affect of grain boundaries. The dependence of $\left(\rho_{f} / \rho_{g}\right)$ on $(t)$ obtained was compared with the theoretical values of $\left(\rho_{f} / \rho_{g}\right)$ according to Tellier theory Fig. 2. Excellent agreement is obviously seen. Mayadas-Shatzkes [6] showed that the presence of the grain boundary scattering reduces the mean free path of carriers, thereby reuslting in an increase in 


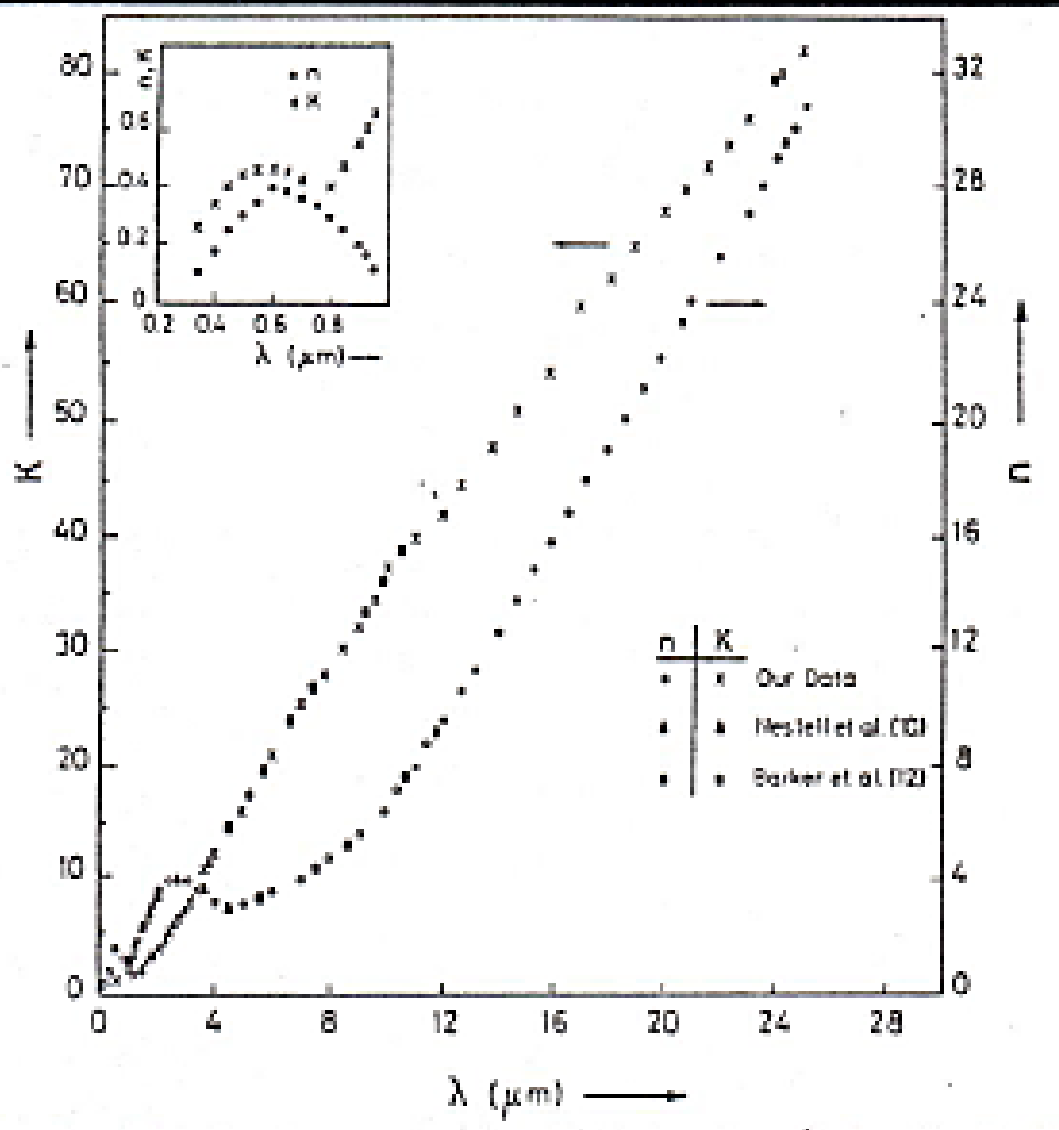

Fig. 3. Relation between $\mathrm{n}(0)$ and $\mathrm{K}(x)$ against $(\lambda)$ for thin $\mathrm{Cr}$ filuns.

Fig. 4.

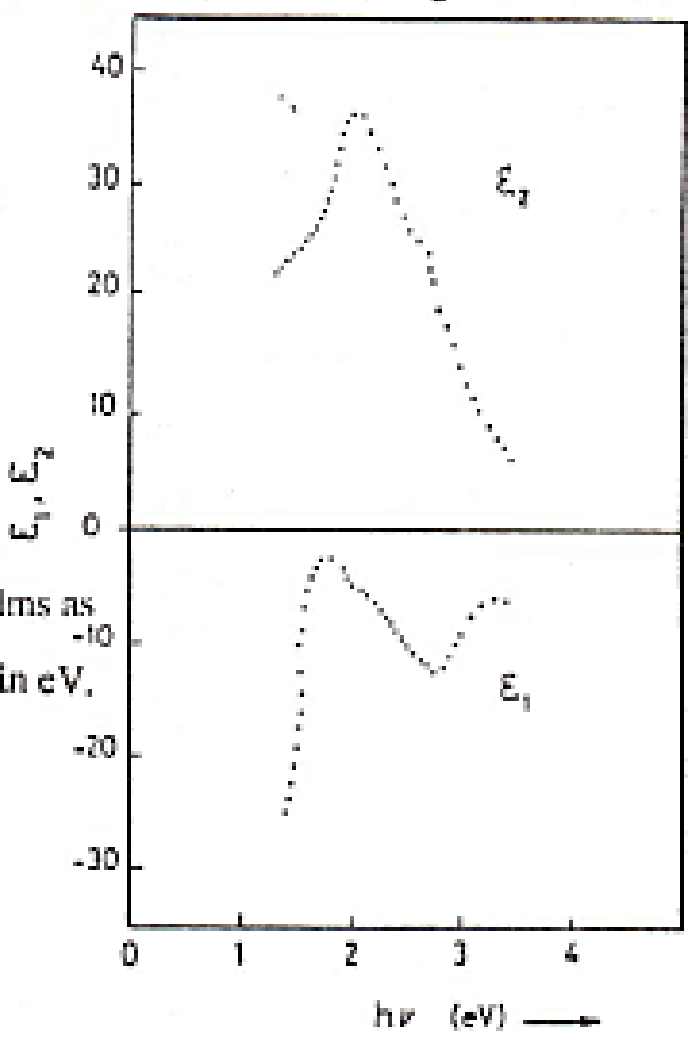

Diclectric constants for $\mathrm{Cr}$ tilms as in function of photon energy in eV. 
resistivity. They showed that $\rho_{\mathrm{g}} 1_{\mathrm{g}}=\rho_{\mathrm{o}} 1_{0}$ where $\rho_{\mathrm{g}}$ and $\mathrm{l}_{\mathrm{g}}$ are the resistivity and the mean free path of carriers in the bulk with film microstructure, whereas $\rho_{0}$ and $l_{0}$ are for signle crystal. Electron density estimated according to the free electron theory was found to be $1.74 \times 10^{21} \mathrm{~cm}^{-3}$ using the equation [6,11] :

$$
\frac{1}{\rho_{0} l_{0}}=\left(\frac{1}{3 \Pi^{2}}\right)^{1 / 3} \frac{\mathrm{e}^{2} \mathrm{n}^{2 / 3}}{\hbar}=\frac{1}{\rho_{\mathrm{g}} 1_{\mathrm{g}}}
$$

where $h=h / 2 \pi$ and $h$ is Planck's constant and $e$ is the electronic charge. The corresponding Fermi energy in such case is found to be $0.246 \mathrm{eV}$ using the equation :

$$
\mathrm{E}_{\mathrm{F}}=\frac{\hbar^{2}}{2 \mathrm{~m}^{*}}\left(3 \pi^{2} n\right)^{2 / 3}
$$

where $\mathrm{m}^{*}$ is the effective mass of the electron $\left[\mathrm{m}^{*}=9.1 \times 10^{-28}\right]$.

\subsection{OPTICAL MEASUREMENTS}

The obtained experimental results concerning the transimittance of $\mathrm{Cr}$ thin films were used to determine the optical constants ( $\mathrm{n}$ and $\mathrm{K}$ ) following the formula given in $[12,13]$. The refractive index $\mathrm{n}$ as well as the absorption index $\mathrm{K}$ does not depend on the film thickness. All of the results for films of different thicknesses fall within the range of the estimated error "In $\mathrm{K}$ is less than $\pm 1.5 \%$ and $\mathrm{n}$ is less than $\pm 0.4 \%$ ".

\section{2a INTERBAND CONTRIBUTIONS}

Optical transitions in a solid can take place by more than one mechanism, the direct transition from the valence band to the conduction on is well known interband transition. However, at low energy I.R. the most probable mechanism in the intraband band, in which the electron transition takes place between two levels in the same band. In general, the electronic transitions in a solid are more directly related to the complex dielectric constant $\bar{\varepsilon}=\varepsilon_{1}+\mathrm{i} \varepsilon_{2}$ instead of the complex index of refraction $n=$ $n+i K$, where $\varepsilon=n^{2}[14]$. So that $\varepsilon_{1}=n^{2}-K^{2}$ and $\varepsilon_{2}=2 n k$. On the other hand, the dielectric constants $\varepsilon_{1}$ and $\varepsilon_{2}$ are closely related to the electronic structure of the solids and are more direcly comparable with theory. Obtained dielectric conststants for $\mathrm{Cr}$ are presented in Fig. 4, where the curves represent the average of values from 
four films of thickness $28,30,34$ and 40 nu respectively. The agrtement of the four results is well within the estanand trror. It is clear from Fig. 4 that therc are two peaks at hv $=2 \mathrm{eV}$ and hy $=1.75 \mathrm{eV}$ for $\varepsilon_{1}$ and $\mathrm{c}_{2}$ respecitively. However, for graphical representacion of the resuls in case of the transition metals, the real and imginary parts of the optical conductivity ane more convenient. The optical conductivity $\sigma_{1}$ and $\sigma_{2}$ ) are related to the components of the complex dielectric constant by $\sigma_{1}=\varepsilon_{2} \alpha / 4 \pi$

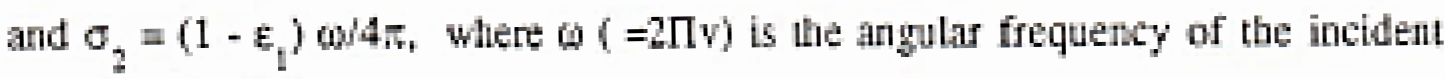
radiation; the feal and inaginary pans of the optical conductivity of thin Cr filuns are shown in Fig. 5. Several attempls have ben made previously to deterniue the freeelectron contribution by extending rellection measurenents further into the infared region. Lenbaur and Trehemelaj made neasurenents up to $15 \mu \mathrm{m}$ for most of the metals including the chromium. Barker and Dizenberger nol used a free-electron gas model to estimate the size of the anonalous skin effect and to calculate the corresponding absoptivity for chroniun. Both the theorerical prediction [1s and the experimental evidence [15] indieate that below $2 \mu \mathrm{m}$ all the measurements are presumed to be enetirely wichin the interbaud portion of the spectrom.

Accordingly, we can consider thal the interband mechanisan, is responsible for the inleraction in the considered spectral negion (twetcw). In this interband region of the spectrum, we will compare our resuls with a recent calculation of optical conductivity, Moruzzi, Williams and Janak[2] have calculated the inturband contribution to $\varepsilon_{2}$ for $\mathrm{Cr}$. These self-consistent effective one-efectron calculations, used the approximation treatment of exchange and correlation due to Koba and Shan,[17], and the "muffin-tin" approximation to bolh the charge deusity and the potential. The resules are conpired with the obbinted experimenal valus of $\sigma_{1}$ in Fig. 6. The agrement is encourging de experimental penk near $2 \mathrm{eV}$ can be correlated with the theoretical one, but it is generally bruader and lower than the theorecical one. This difference may be parly because the measurements were made at room temperature, and that the temperature dependence tan be strong enough to account for 
Fig. 5

Optiunal conductivity in $10^{-15} \mathrm{~s}^{-1}$ for Cr tilms as a function of phomesn energy in ev.

Fig. 6.

Our experimental optical conductivity (SAM) compared with the theoretical curve of Moruzzi, Williams and Janak (MWJ).

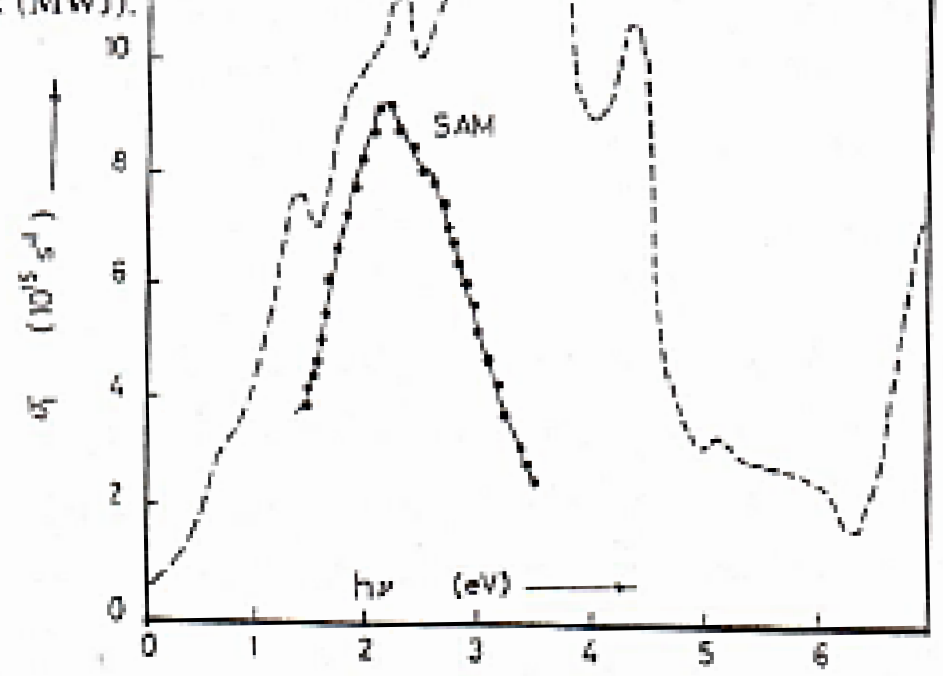




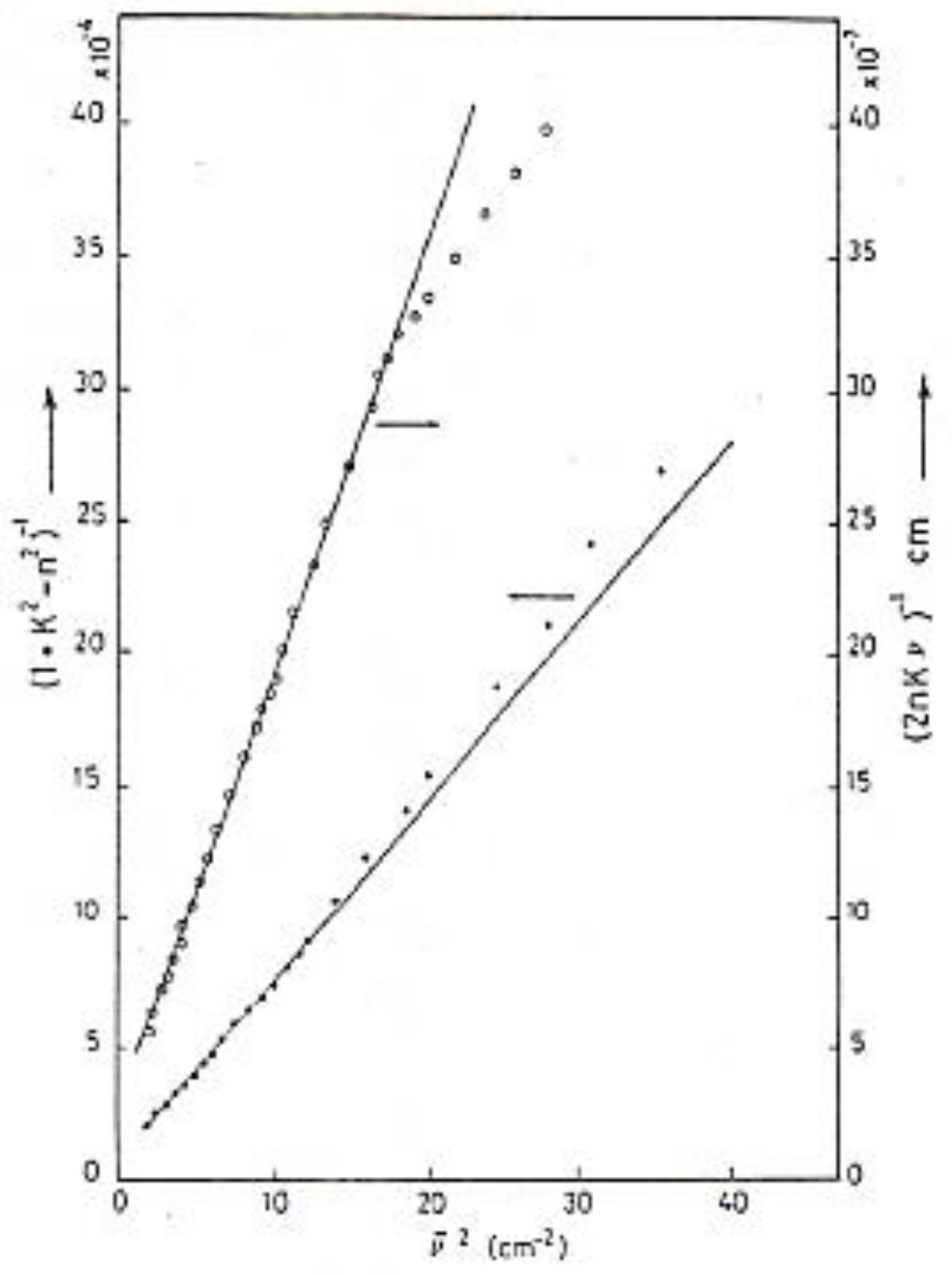

Fig. 7. Relation between $\left(1+\mathrm{K}^{2} \cdot \mathrm{n}^{2}\right)$ and $(2 \mathrm{nKn})^{-1}$ with $v^{-2}$ for $\mathrm{Cr}$ thin films. 
the entire discrepancies. The theoretical curves of Cr bave a peak just above $2 \mathrm{eV}$ comesponding to $3 \rightarrow 4$ transitions. Contributions are coning from transitions over a large wolume of $\mathrm{k}$ spece along the thee mijor directions $(A, \Delta$ and 2$)$. The $3-4$ Iransitions corresponding to the $2 \mathrm{cV}$ peak probubly occur away from a symuetry point along $\mathrm{A}$ of near $\mathrm{G}$.

\section{2b INTRABAND CONTRIEUTIONS:}

Most stides in which the intraband and interband processes have becn separated, have been separaicd, have used the Drode theory [18]. According to the previous theory, there are wo relations relating the optical constants $(\mathrm{n}$ and $\mathrm{K}$ ) to the wavenumber of the incident radiation (v). These wo relations are:

$$
\left(1+K^{2}-n^{2}\right)^{-1}=(v)^{2}\left[(w)^{2}+(v)^{2}+\left[v_{R}\right)^{2}\right]
$$

and

$$
(2 n K \bar{v})^{-1}=\left(\overline{v_{0}}\right)^{2}\left(\bar{v}_{\mathrm{R}}\right)^{1}\left[(\bar{v})^{2}+\left(\overline{v_{\mathrm{K}}}\right)^{2}\right]
$$

where $\bar{v}_{0}$ is the plasma frequency and $\bar{v}_{\mathrm{g}}$ is the damping frequency. Thus the

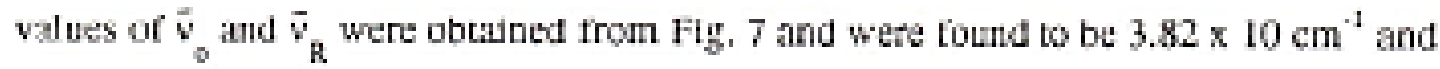
$413.3 \mathrm{~cm}^{-4}$ respectively. In addition to equations (5) and (6),

$$
(\bar{v})^{2}=\mathrm{b}_{\mathrm{c}} \mathrm{e}^{2} \Pi \Pi \mathrm{mi}^{*} \mathrm{c}^{2}
$$

and

$$
\vec{v}_{\mathrm{H}}=1 / 2 \pi \mathrm{ct}
$$

Where $n_{\varepsilon}$ is the number of conduction electrons per unit volume, the electron charge, the relaxition time, $m^{*}$ the affective mass and c lie light velocity in vacuum. Using the values of $\bar{v}_{0}$ and $\bar{v}_{\mathrm{E}}$ in conjunction with equations (7) and $(8) \mathrm{n}_{\mathrm{a}^{*}} \bar{t}$ were culculated and are given in Table (1). Tuking into account that $\mathrm{m}^{*}=\mathrm{m}=9.1 \times 10^{34} \mathrm{gm}$. Krowing $a$ and $\tau$ the stitc conductivity (o) in Cr films can be colculated using-

$$
\theta=\mathrm{ne}^{2} \mathrm{c} / \mathrm{m}^{4}
$$


It was found that $s=5.28 \times 1016$ (e.s.u.). The electron velocity at the Fermi surface $\mathrm{V}_{F}$ can be determined using the following equation :

$$
V_{F}=\left(3 n_{c} h^{3} / 8 m^{* 2} e^{2}\right)^{1 / 3}
$$

$V_{F}$ was calculated and tabulated in Table (1). It was possible to define $l_{\mathrm{g}}$ the mean free path by using the formula $l_{g}=\tau V_{F}$. It was found that $l_{z}=19.9 \mathrm{~nm}$. The small values of $\mathrm{I}_{\mathrm{g}}$ indicate that electrons are strongly interacting with each other and with lattice. This is a known effect for transition metals, which are chanacterized by a narow $3 \mathrm{~d}$ band. All the calculated parameters using the optical properties are given in Table (1) in comparison with those obtained previously from the electrical measurements.

Table. 1.: Values of $\mathrm{n}_{\mathrm{c}}, \sigma, \tau, \mathrm{l}_{\mathrm{n}}$ and $\mathrm{E}_{\mathrm{F}}$ determined from electrical measurements compared with that obtained from optical measurements.

\begin{tabular}{||c|c|c|c|c|c|c|}
\hline & $\mathrm{n}_{\mathrm{c}} \mathrm{cm}^{\cdot 3}$ & $\sigma e s u$ & $\tau(\mathrm{s})$ & $\mathrm{I}_{\mathrm{g}} \mathrm{nm}$ & $\mathrm{E}_{\mathrm{f}} \mathrm{cV}$ & $\mathrm{V}_{\mathrm{F}} \mathrm{cm} / \mathrm{s}$ \\
\hline Electrical & $1.74 \times 10^{21}$ & $2.4 \times 10^{16}$ & - & 22.5 & 0.246 & - \\
\hline Optical & $1.63 \times 10^{22}$ & $5.28 \times 10^{16}$ & $1.28 \times 10^{14}$ & 19.9 & 0.234 & $1.55 \times 10^{8}$ \\
\hline
\end{tabular}




\section{REFERENCES}

1. M. Suffczynski, phys. nev. $117,3(1960)$.

2. V.L. Monızzi, A. R. Willians, and J.F. Janak, Phys, rev, letters, 28,671 (1972).

3. J. Callaway and C. Wang, Phys, rew, B7, 1096 (1973).

4. E.H. Sondheimer, Adv. Pbys. 1, 1 (1973).

5- J. E. Nestell, Jr. and R. W. Christy, J. Vac. Sci. Technol, 15, 366 (1978).

6 AS. F. Mayadas and M. Shatzkes, Phys. Rev, Bl. 1382 (1970).

7. EE. Mola and J. M. Heras, Thin Solid Films 18.137 (1973).

8. C. R. Tellier, A. J. Tosser and C. Boutrit, ibid, 44, 201 (1978).

9. C. R. Pichard, C.R. Tellier, and A.J. Tosser, J. Phys, F. Metal Phys. 10, 2009 (1980).

10- L.A. Udachan, S.M. Shivaprasad, P.V. Ashrit, and M.A. Angadi, Phys. Stat. sol. (a) $60.191(1980)$.

11 - V. Damodan Das, N. Soundakarajan, J. Mat, Sci, 24,4315 (1989),

12. L.N. Hadley and D.M. Dennison, J. Opt. Soc. Am, 37, 451 (1947).

13. L. Harris and A.L. Loeb, J. Opt. Soc. Ann. 45, 179 (1955).

14. J.E. Nestell, Js. and R. W. Christy, Appl. Opt. 11, 643 (1972)

15. A. P. Lenham and D.M. Trecherne, In Optical Properties and Electronic Strueture of Metats and Alloys. (Nort: Holland, Amstetdan, 1966) 196-201.

16. A. S. Barker, Jr. and J. A. Ditzenberger, Phyz: Rev, Bl, 4378 (1970).

17. W. Kohn and L.J. Stann, Phys, rev, 140, Al133 (1965).

18- P. Drude, Appl, Sci. Res. B2, 169 (1953). 